\title{
Expression of coxsackie and adenovirus receptor is correlated with inferior prognosis in liver cancer patients
}

\author{
XUE YANG ${ }^{1,2^{*}}$, SHUANGSHUANG $\mathrm{LI}^{1,2^{*}}$, HUIJU WANG $^{1,3}$, WANYUAN CHEN $^{4}$, \\ XIAOZHOU MOU ${ }^{1,2}$ and SHIBING WANG ${ }^{1,2}$
}

\author{
${ }^{1}$ Clinical Research Institute, Zhejiang Provincial People's Hospital, People's Hospital of Hangzhou Medical College; \\ ${ }^{2}$ Key Laboratory of Tumor Molecular Diagnosis and Individualized Medicine of Zhejiang Province; ${ }^{3}$ Key Laboratory of \\ Gastroenterology of Zhejiang, Zhejiang Provincial People's Hospital; ${ }^{4}$ Department of Pathology, \\ Zhejiang Provincial People's Hospital, People's Hospital of Hangzhou \\ Medical College, Hangzhou, Zhejiang 310014, P.R. China
}

Received April 25, 2018; Accepted December 7, 2018

DOI: $10.3892 / \mathrm{ol} .2018 .9868$

\begin{abstract}
The coxsackie and adenovirus receptor (CAR), a tumor suppressor, is vital for the effectiveness of therapies which utilize the adenovirus. However, studies on CAR expression in hepatocellular carcinoma (HCC) are conflicting and its clinical significance requires exploration. In this study, immunohistochemistry has been carried out on tissue microarrays consisting of 198 pairs of HCC and neighboring healthy tissue specimens from Chinese Han patients to evaluate CAR expression. Relative to normal tissues, decreased CAR expression $(56 \%$ vs. $57 \%$; $\mathrm{P}>0.05)$ was detected in HCC samples. CAR immunopositivity in tumors was not dependent upon sex, age, tumor dimensions, differentiation, TNM stage or metastasis in HCC patients; however, positive expression was observed in $56 \%$ of the samples from patients with hepatic metastasis, which was the same as those devoid of metastasis $(56 \% ; \mathrm{P}=0.042)$. Furthermore, survival analysis confirmed that the expression of CAR revealed no correlation with the prognosis. It was established that CAR exerted complex effects during liver tumorigenesis, potentially based on the stage of the cancer. Therefore, CAR expression analysis has to be carried out prior to adenoviral oncolytic therapy to stratify the patients.
\end{abstract}

Correspondence to: Dr Shibing Wang, Clinical Research Institute, Zhejiang Provincial People's Hospital, People's Hospital of Hangzhou Medical College, 158 Shangtang Road, Hangzhou, Zhejiang 310014, P.R. China

E-mail: wangshibing@hmc.edu.cn

${ }^{*}$ Contributed equally

Key words: coxsackie and adenovirus receptor, liver cancer, adenovirus, Chinese Han patients, immunohistochemistry

\section{Introduction}

Hepatocellular carcinoma (HCC) is a common solid tumor displaying inferior prognosis and a high recurrence rate, which results in extensive worldwide mortality (1). Due to the development of innovative treatments like hepatic transplantation, hepatic resection, chemotherapy, and radiofrequency ablation, the survival rates of patients have improved (2); however, an effective treatment for the complete cure of HCC has yet to be developed. Although significant efforts have been made to elucidate the disease progression and to develop valuable therapies, the molecular mechanisms in HCC are still mostly unknown. Hence, there is an imperative need to enhance the prognosis of the disease. Oncolytic viruses (OVs), which can be engineered to selectively replicate intracellularly and destroy tumor tissues, have been applied as an efficacious solution against tumors. Numerous OVs have been designed to exploit their antitumor effects; for instance, pexastimogene devacirepvec (Pexa-Vec) is currently in a phase III trial for the treatment of HCC (3). In this context, the safety and efficacy of adenovirus vectors for gene delivery should also be demonstrated in the future.

The coxsackie and adenovirus receptor (CAR), a transmembrane constituent of the tight junctions in epithelial tissue, has been originally discovered as a viral attachment site that is essential for virus uptake (4). Walters et al (5) established the role of CAR in gene transfer and as a principal receptor for the coxsackie B virus and adenovirus. Pandha et al (6) demonstrated that CAR expression was strongly correlated with adenovirus infection, adhesion and transgene expression. Attenuated adenoviruses, which may be replication-incompetent to transmitted therapeutic genes or viruses, can be employed in cancer therapy (7). Therefore, the expression of CAR is considered a crucial factor for the effectiveness of adenovirus-based therapeutics.

Analysis of CAR expression in several classes of tumors produced diverse results. It has been reported that CAR expression was low in colon, lung and bladder (8-11) tumors, predominantly in poorly differentiated and advanced-stage cancers $(9,12,13)$. Additionally, downregulated CAR expression predicted an inferior clinical result for gastric and 
bladder cancer patients $(9,14)$. Contrastingly, CAR upregulation has been detected in endometrial, ovarian, cervical and breast cancers, along with neuroblastomas and medulloblastomas (15-20). Moreover, elevated CAR expression was correlated with inferior prognosis in breast and lung cancers $(12,21)$. Therefore, there is a need to confirm if these outcomes indicate a disparity in CAR expression or a result from racial and procedural variations.

In the present investigation, immunohistochemistry was employed to evaluate CAR expression in HCC and neighboring healthy tissue specimens in tissue microarrays (TMAs). A greater sample size was chosen to acquire data for an improved understanding of the function of CAR in the progression of HCC. Additionally, probable targets for adenovirus-mediated therapeutic strategies related to CAR expression were established.

\section{Materials and methods}

HCC patients in tissue microarray. HCC protein expression levels were assessed with immunohistochemical staining of tissue microarrays, which were purchased from Shanghai Biochip Co., Ltd. (Shanghai, China). The patient samples were collected from Zhejiang Provincial People's Hospital (Hangzhou, China) and all patients provided written informed consent. The study was approved by the Ethics Committee of Zhejiang Provincial People's Hospital. The TMAs contained a total of 396 formalin-fixed, paraffin-embedded archived samples from a total of 198 HCC patients from the Chinese Han population, in addition to 198 corresponding controls derived from adjacent normal tissue samples.

The patient cohort consisted of 159 males and 39 females, with a median age of 55 years (range, 27-91 years) at the time of surgery. All patients had follow-up records for $>5$ years. The survival time was calculated from the date of surgery to the follow-up deadline or mortality.

Immunohistochemical staining. Immunohistochemical staining was performed according to the standard method. Briefly, $5-\mu \mathrm{m}$ sections from the TMAs were baked at $70^{\circ} \mathrm{C}$ for $2 \mathrm{~h}$. Then, the sections were de-paraffinized in xylene, rehydrated using a gradient of ethanol concentrations, boiled in $1 \mathrm{mM}$ TE buffer with a high-pressure cooker for $3 \mathrm{~min}$ for antigen retrieval, blocked with $3 \%$ hydrogen peroxide for $15 \mathrm{~min}$ to inhibit endogenous peroxidase activity and incubated with $10 \%$ goat non-immune serum (Invitrogen; Thermo Fisher Scientific, Inc., Waltham, MA, USA) for $20 \mathrm{~min}$ to reduce background non-specific staining. Subsequently, TMA sections were incubated with rabbit anti-human primary polyclonal antibody against CAR (dilution, 1:400; cat.no. Sc-15405; Santa Cruz Biotechnology, Inc., Dallas, TX, USA) overnight at $4^{\circ} \mathrm{C}$, and then incubated with biotin-labeled secondary antibody (1:200; cat. no. AB-2548649) at room temperature for $15 \mathrm{~min}$, followed by incubation with HRP-conjugated streptavidin (1:100; cat. no. AB-11155398; both Invitrogen; Thermo Fisher Scientific, Inc) at room temperature for $15 \mathrm{~min}$. Then, color development was performed with a DAB Substrate kit (Dako, Glostrup, Denmark). Finally, the sections were counterstained with hematoxylin, dehydrated, cleared and mounted.
Evaluation of the immunohistochemical stainings. Immunohistochemical stainings of CAR were scored by two pathologists independently, based on the intensity and the proportion of positively stained cells. Staining intensity was evaluated with a four-tiered grading system: 0 , negative; 1, weak; 2, moderate; and 3, strong. The percentage of positive cells were scored as follows: 0 , no cells stained, $1,1-25 \%$ of cells stained; $2,26-50 \%$ of cells stained; $3,51-75 \%$ of cells stained; and $4,>75 \%$ of cells stained. Scores for intensity and percentage of positive cells were multiplied. Scores $\leq 6$ were used to define tumors with low CAR expression and scores $>6$ with high CAR expression.

Statistical analysis. Statistical analysis was performed using Statistical Program for Social Sciences (SPSS) software 13.0 (SPSS Inc., Chicago, IL, USA). The $\chi^{2}$-tests were applied to assess the statistical significance of the associations between CAR expression and clinicopathological parameters, respectively. Cox proportional hazards regression model was used to perform multivariate survival analysis to assess predictors associated with prognosis. $\mathrm{P}<0.05$ was considered to indicate a statistically significant difference.

\section{Results}

CAR expression in HCC is inferior to that in adjacent healthy tissue samples. Immunohistochemistry was employed to evaluate the distribution of HCC, where immunostaining of the tissues predominantly affected the cell membrane and cytoplasm (Fig. 1). Positive CAR expression was observed in 114 out of 198 (57\%) normal liver tissue samples, which was slightly superior to that of $\operatorname{HCC}\left(56 \%, 111 / 198, \chi^{2}=174.7\right.$, $\mathrm{P}>0.05)$.

Patient characteristics and the association between CAR expression and clinicopathological parameters of $H C C$. With the aim of exploring whether CAR is related to HCC progression, the expression of CAR was studied with respect to clinicopathological features in HCC. The outcomes established that the occurrence of CAR immunopositivity was not significantly dependent upon sex, age, metastasis, microvascular invasion, HBs antigen, cirrhosis and AFP (Table I).

Survival analysis reveals that CAR immunopositivity does not significantly diminish survival times. The average survival time of CAR-positive liver cancer patients (42.201 \pm 4.056 months) was not significantly different than that of CAR-negative patients $(40.934 \pm 3.409$ months, $\mathrm{P}=0.240$ ). The Kaplan-Meier survival curve indicated that CAR expression was not significantly associated to overall survival in HCC patients (Fig. 2). Additionally, the prognosis factors of HCC were analyzed by Cox-regression analysis. Univariate analysis indicated that tumor size $(\mathrm{P}=0.005)$, metastasis $(\mathrm{P}<0.001)$, microvascular invasion $(\mathrm{P}=0.016)$, Edmondson grade $(\mathrm{P}<0.001)$ and $\mathrm{AFP}(\mathrm{P}=0.002)$ were independent prognostic factors in patients with HCC. Multivariate analysis revealed that distant metastases $(\mathrm{P}<0.001)$, tumor number $(\mathrm{P}=0.001)$, Edmondson grade $(\mathrm{P}=0.028)$ and AFP $(\mathrm{P}=0.008)$ were independent prognostic factors for patients with HCC (Table II). 
Table I. Expression of CAR in HCC tissues.

\begin{tabular}{|c|c|c|c|c|}
\hline \multirow[b]{2}{*}{ Clinical parameters } & \multirow[b]{2}{*}{ No. } & \multicolumn{2}{|c|}{$\begin{array}{c}\text { CAR } \\
\text { expression }\end{array}$} & \multirow[b]{2}{*}{ P-value } \\
\hline & & Low & High & \\
\hline Age, years & & & & 0.989 \\
\hline$<55$ & 75 & 33 & 42 & \\
\hline$\geq 55$ & 123 & 54 & 69 & \\
\hline Sex & & & & 0.303 \\
\hline Male & 159 & 67 & 92 & \\
\hline Female & 39 & 20 & 19 & \\
\hline Size, $\mathrm{cm}$ & & & & 0.019 \\
\hline$<5$ & 100 & 36 & 64 & \\
\hline$\geq 5$ & 95 & 50 & 45 & \\
\hline Tumor number & & & & 0.407 \\
\hline Single & 161 & 73 & 88 & \\
\hline Multiple & 37 & 14 & 23 & \\
\hline Edmondson grade & & & & 0.009 \\
\hline $\mathrm{I}+\mathrm{II}$ & 127 & 47 & 80 & \\
\hline III & 71 & 40 & 31 & \\
\hline Metastasis & & & & 0.987 \\
\hline M0 & 182 & 80 & 102 & \\
\hline M1 & 16 & 7 & 9 & \\
\hline Microvascular invasion & & & & 0.880 \\
\hline Absence & 65 & 33 & 32 & \\
\hline Presence & 73 & 38 & 35 & \\
\hline HBs antigen & & & & 0.744 \\
\hline Negative & 43 & 18 & 25 & \\
\hline Positive & 150 & 67 & 83 & \\
\hline Cirrhosis & & & & 0.701 \\
\hline Negative & 62 & 26 & 36 & \\
\hline Positive & 136 & 61 & 75 & \\
\hline AFP & & & & 0.274 \\
\hline$<50$ & 101 & 44 & 57 & \\
\hline$\geq 50$ & 97 & 49 & 48 & \\
\hline
\end{tabular}

Bold indicates a statistically significant result. CAR, coxsackie and adenovirus receptor; HCC, hepatocellular carcinoma.

\section{Discussion}

HCC is a common lethal cancer which leads to large-scale mortality worldwide (22). At present, there are numerous limitations to the treatment of HCC; hence, there is a necessity for the development of innovative and efficient therapeutics (23-25). It has been reported that low expression of CAR was detected in colon, lung and bladder (8-11) tumors and downregulated CAR expression predicted an inferior clinical result for gastric and bladder cancer patients $(9,14)$. Conversely, CAR upregulation has been detected in endometrial, ovarian, cervical, breast cancers, along with neuroblastomas and medulloblastomas (15-20). Moreover, increased CAR expression was correlated with inferior prognosis in breast and
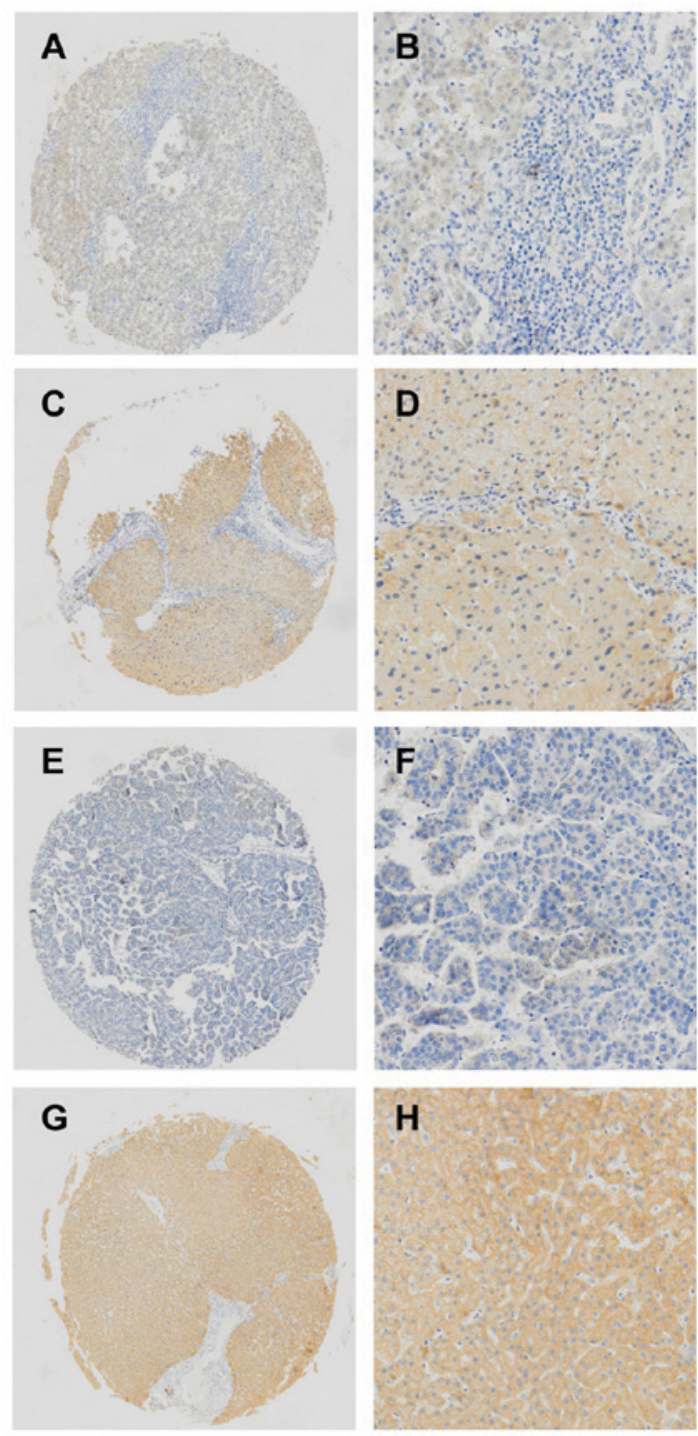

Figure 1. Immunohistochemical analysis of CAR in liver cancer and normal tissues. (A and B) Low expression of CAR in normal liver tissues adjacent to cancerous tissues. (C and D) High expression of CAR in normal liver tissues adjacent to cancerous tissues and positive staining, primarily in the membrane and cytoplasm. (E and F) Low expression of CAR in the tumor sample. $(\mathrm{G}$ and $\mathrm{H}) \mathrm{High}$ expression of CAR in the tumor sample and positive staining, mainly in the membrane and cytoplasm. (A, C, E, and G) Original magnification, x200; (B, D, F, and H) original magnification, x800. CAR, Coxsackie and adenovirus receptor.

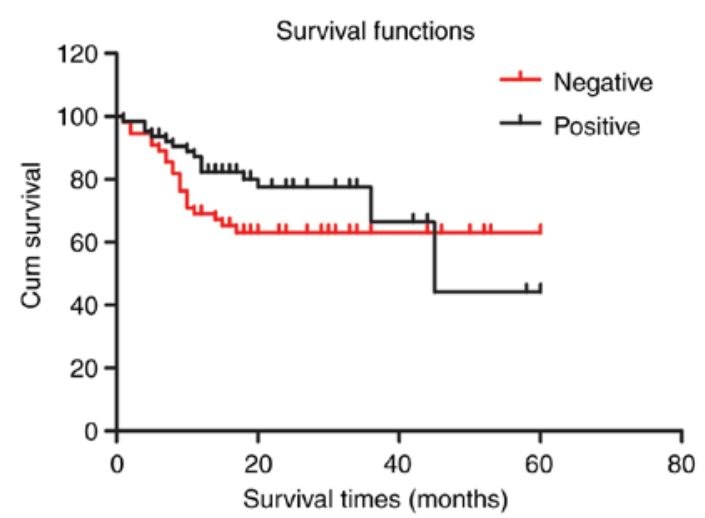

Figure 2. Estimation of Kaplan-Meier survival curves in CAR-positive and CAR-negative patients indicating that CAR expression displayed no notable association with overall survival. 
Table II. Univariate and multivariate Cox-regression analyses of the clinicopathological features in HCC patients.

\begin{tabular}{|c|c|c|c|c|c|c|c|}
\hline \multirow[b]{2}{*}{ Parameters } & \multirow[b]{2}{*}{ No. } & \multicolumn{3}{|c|}{ Univariate analysis } & \multicolumn{3}{|c|}{ Multivariate analysis } \\
\hline & & HR & $95.0 \% \mathrm{CI}$ for $\mathrm{HR}$ & P-value & $\mathrm{HR}$ & $95.0 \% \mathrm{CI}$ for $\mathrm{HR}$ & P-value \\
\hline Age $(<55$ years $/ \geq 55$ years $)$ & $75 / 123$ & 0.651 & $0.409-1.038$ & 0.071 & 0.335 & $0.119-0.943$ & 0.058 \\
\hline Sex (male/female) & $159 / 39$ & 1.575 & $0.922-1.575$ & 0.096 & 0.623 & $0.202-1.922$ & 0.410 \\
\hline Tumor size $(<50 \mathrm{~mm} / \geq 50 \mathrm{~mm})$ & $100 / 95$ & 1.954 & $1.219-3.132$ & 0.005 & 1.425 & $0.423-4.799$ & 0.567 \\
\hline Tumor number (single/multiple) & $161 / 37$ & 1.239 & $0.678-2.264$ & 0.487 & 11.26 & $2.573-49.279$ & 0.001 \\
\hline Metastasis(M0/M1) & $182 / 16$ & 4.821 & $2.551-9.112$ & $<0.001$ & 26.004 & $5.762-7.352$ & $<0.001$ \\
\hline Microvascular invasion $(-/+)$ & $65 / 73$ & 1.89 & $1.127-3.171$ & 0.016 & 0.688 & $0.216-2.194$ & 0.527 \\
\hline Edmondson grade (I+II/III) & $127 / 71$ & 2.783 & $1.735-4.464$ & $<0.001$ & 2.984 & $1.124-7.923$ & 0.028 \\
\hline Cirrhosis (-/+) & $62 / 136$ & 1.153 & $0.698-1.905$ & 0.577 & 3.52 & $0.949-10.052$ & 0.06 \\
\hline $\operatorname{AFP}(<50 \mu \mathrm{g} / \mathrm{l} / \geq 50 \mu \mathrm{g} / \mathrm{l})$ & $101 / 97$ & 2.51 & $1.395-4.517$ & 0.002 & 4.245 & $1.455-12.386$ & 0.008 \\
\hline CAR expressions (-/+) & $88 / 110$ & 0.667 & $0.345-1.289$ & 0.228 & 0.677 & $0.206-2.225$ & 0.520 \\
\hline
\end{tabular}

Bold indicates a statistically significant result. HCC, hepatocellular carcinoma; HR, hazard ratio; CAR, coxsackie and adenovirus receptor; CI, confidence interval.

lung cancers $(12,21)$. However, in the present study, relative to normal tissues, slightly decreased CAR expression was detected in HCC samples and the Kaplan-Meier survival curve indicated that CAR expression was not significantly associated to overall survival in HCC patients. CAR immunopositivity in tumors was not dependent upon sex, age, differentiation or metastasis in HCC patients, which was in agreement with earlier observations by Stecker et al (26). Also, positive expression was observed in $56 \%$ of the samples from patients with hepatic metastasis, which was the same as those devoid of metastasis. Although, the relevant molecular mechanism is important, a limitation of this study is that it lacks some functional experiments to study the relevant mechanisms. In subsequent studies, with the purpose of exploring the relevant molecular mechanisms of CAR, CAR expression will be altered (downregulation and upregulation), followed by the detection of the expression of related genes through fluorogenic quantitative PCR and western blotting.

Recently, cancer virotherapy, principally mediated by oncolytic viruses (OVs), has gained popularity as a new and potent strategy in the field of cancer therapy (27-29). Consequently, the safety and efficacy of adenovirus vectors for gene delivery should also be illustrated in the future. The first OV therapy for cancer was approved in 2015 after more than a century of extensive research. However, this is considered as a modest victory when compared to the numerous small molecule anticancer agents and antibody therapies that have gained approval for clinical use over the previous thirty years. Although OVs are markedly effective as anticancer agents with low toxicity in vitro and in vivo, their efficacy as a single agent therapy is limited. In this context, a combination of gene therapy and therapeutically valuable OVs, such as oncolytic adenoviruses (OAds), is one of the most potent therapeutic approaches. Furthermore, OAds have been genetically improved to take advantage of the altered tumor environment.

In the last twenty years, viral and non-viral vector-mediated gene therapy has been established as a potential therapeutic strategy for a range of cancers and other serious diseases which would otherwise be deemed incurable with traditional drugs (28). Previously, several trials focusing on the combination of OAds with immunostimulatory-, proapoptotic- or tumor suppressor genes were carried out and revealed enhanced antitumor potency (28,30-33). Clinically detected cancers may have escaped antitumor immune mechanisms during their growth; hence, the probability of potent immunotherapies for their cure is currently becoming a clinical reality (34). Furthermore, a circadian crosstalk exists among OAds, TRAIL and IL-12 in the stimulation of antitumor immunity (35). Angiogenesis is vital for tumorigenesis; accordingly, several studies have ascertained that OAds can impair tumor-mediated angiogenesis (36). Apoptosis is a programmed cell death process which eliminates cancer cells and other detrimental cells to sustain homoeostasis; thus, it presents a potential target for innovative cancer therapeutics. In this context, a combination therapy of OAd-expressing TRAIL with an additional type of immunostimulant cytokine (IL-24) was demonstrated to be related to the activation of an apoptotic caspase cascade (primarily caspases-3 and -8) in HCC (37).

A future direction of cancer research is to find a new combination therapy with OAds to treat tumors. Conversely, CAR is vital for ensuring virus uptake, gene transfer and acts as a principal receptor for the coxsackie B virus and adenovirus. In summary, CAR expression could serve as a biomarker for studying and estimating the results of gene therapy, and increasing its expression may enhance cellular sensitivity to adenovirus infection. Therefore, there is a potential need to research new therapies and to detect the expression of the CAR, concurrently.

\section{Acknowledgements}

Not applicable.

\section{Funding}

The present article was supported by the National Science Foundation of China (nos. 81602706 and 81570198), 
funds from the Department of Science Technology of Zhejiang Province (no. 2017C33116), the Zhejiang Medical Technology Plan Project (no. 2016KYA018), and the State Administration of Traditional Chinese Medicine of Zhejiang (no. 2017ZB006).

\section{Availability of data and materials}

The datasets used during the present study are available from the corresponding author upon reasonable request.

\section{Authors' contributions}

SW and XM conceived and designed the study. XY, SL, HW and WC performed the experiments. XY wrote the paper. HW, WC, XM and SW reviewed and edited the manuscript. All authors read and approved the manuscript and agree to be accountable for all aspects of the research in ensuring that the accuracy or integrity of any part of the study are appropriately investigated and resolved.

\section{Ethics approval and consent to participate}

The patient samples were collected from Zhejiang Provincial People's Hospital and all patients provided written informed consent. The study was approved by the Ethics Committee of Zhejiang Provincial People's Hospital.

\section{Patient consent for publication}

Not applicable.

\section{Competing interests}

The authors declare that they have no competing interests.

\section{References}

1. Jemal A, Bray F, Center MM, Ferlay J, Ward E and Forman D: Global cancer statistics. CA Cancer J Clin 61: 69-90, 2011.

2. Altekruse SF, McGlynn KA, Dickie LA and Kleiner DE: Hepatocellular carcinoma confirmation, treatment, and survival in surveillance, epidemiology, and end results registries, 1992-2008. Hepatology 55: 476-482, 2012.

3. US National Library of Medicine. ClinicalTrials. gov http://www.Clinicaltrials.gov/ct2/Show/NCT02562755, 2015.

4. Cohen CJ, Shieh JT, Pickles RJ, Okegawa T, Hsieh JT and Bergelson JM: The coxsackievirus and adenovirus receptor is a transmembrane component of the tight junction. Proc Natl Acad Sci USA 98: 15191-15196, 2001.

5. Walters RW, Freimuth P, Moninger TO, Ganske I, Zabner J and Welsh MJ: Adenovirus fiber disrupts CAR-mediated intercellular adhesion allowing virus escape. Cell 110: 789-799, 2002.

6. Pandha HS, Stockwin LH, Eaton J, Clarke IA, Dalgleish AG, Todryk SM and Blair GE: Coxsackie B and adenovirus receptor, integrin and major histocompatibility complex class I expression in human prostate cancer cell lines: Implications for gene therapy strategies. Prostate Cancer Prostatic Dis 6: 6-11, 2003.

7. Kasuya H, Takeda S, Shimoyama S, Shikano T, Nomura N, Kanazumi N, Nomoto S, Sugimoto H and Nakao A: Oncolytic virus therapy-foreword. Curr Cancer Drug Targets 7: 123-125, 2007.

8. Abdolazimi Y, Mojarrad M, Pedram M and Modarressi MH: Analysis of the expression of coxsackievirus and adenovirus receptor in five colon cancer cell lines. World J Gastroenterol 13: 6365-6369, 2007.
9. Anders M, Vieth M, Rocken C, Röcken C, Ebert M, Pross M, Gretschel S, Schlag PM, Wiedenmann B, Kemmner W and Höcker M: Loss of the coxsackie and adenovirus receptor contributes to gastric cancer progression. Br J Cancer 100: 352-359, 2009.

10. Wang Y, Thorne S, Hannock J, Francis J, Au T, Reid T, Lemoine N, Kirn D and Halldén G: A novel assay to assess primary human cancer infectibility by replication-selective oncolytic adenoviruses. Clin Cancer Res 11: 351-360, 2005.

11. Yamashita M, Ino A, Kawabata K, Sakurai F and Mizuguchi H: Expression of coxsackie and adenovirus receptor reduces the lung metastatic potential of murine tumor cells. Int J Cancer 121: 1690-1696, 2007.

12. Wunder T, Schmid K, Wicklein D, Groitl P, Dobner T, Lange T, Anders M and Schumacher U: Expression of the coxsackie adenovirus receptor in neuroendocrine lung cancers and its implications for oncolytic adenoviral infection. Cancer Gene Ther 20: 25-32, 2013.

13. Wunder T, Schumacher U and Friedrich RE: Coxsackie adenovirus receptor expression in carcinomas of the head and neck. Anticancer Res 32: 1057-1062, 2012

14. Matsumoto K, Shariat SF, Ayala GE, Rauen KA and Lerner SP: Loss of coxsackie and adenovirus receptor expression is associated with features of aggressive bladder cancer. Urology 66: 441-446, 2005.

15. Dietel M, Häfner N, Jansen L, Dürst M and Runnebaum IB: Novel splice variant CAR $4 / 6$ of the coxsackie adenovirus receptor is differentially expressed in cervical carcinogenesis. J Mol Med (Berl) 89: 621-630, 2011.

16. Giaginis CT, Zarros AC, Papaefthymiou MA, Papadopouli AE, Sfiniadakis IK and Theocharis SE: Coxsackievirus and adenovirus receptor expression in human endometrial adenocarcinoma: Possible clinical implications. World J Surg Oncol 6: 59, 2008.

17. Martin TA, Watkins G and Jiang WG: The Coxsackie-adenovirus receptor has elevated expression in human breast cancer. Clin Exp Med 5: 122-128, 2005.

18. Martino TA, Petric M, Weingartl H, Bergelson JM, Opavsky MA, Richardson CD, Modlin JF, Finberg RW, Kain KC, Willis N, et al: The coxsackie-adenovirus receptor (CAR) is used by reference strains and clinical isolates representing all six serotypes of coxsackievirus group B and by swine vesicular disease virus. Virology 271: 99-108, 2000.

19. Persson A, Fan X, Widegren B and Englund E: Cell type- and region-dependent coxsackie adenovirus receptor expression in the central nervous system. J Neurooncol 78: 1-6, 2006.

20. Reimer D, Steppan I, Wiedemair A, Concin N, Hofstetter G, Marth C, Müller-Holzner E and Zeimet AG: Soluble isoforms but not the transmembrane form of coxsackie-adenovirus receptor are of clinical relevance in epithelial ovarian cancer. Int J Cancer 120: 2568-2575, 2007.

21. Wang Y, Wang S, Bao Y, Ni C, Guan N, Zhao J, Salford LG, Widegren $\mathrm{B}$ and Fan X: Coxsackievirus and adenovirus receptor expression in non-malignant lung tissues and clinical lung cancers. J Mol Histol 37: 153-160, 2006.

22. Jiang G, Zhang L, Zhu Q, Bai D, Zhang C and Wang X: CD146 promotes metastasis and predicts poor prognosis of hepatocellular carcinoma. J Exp Clin Cancer Res 35: 38, 2016.

23. Stotz M, Gerger A, Haybaeck J, Kiesslich T, Bullock MD and Pichler M: Molecular targeted therapies in hepatocellular carcinoma: Past, present and future. Anticancer Res 35: 5737-5744, 2015.

24. Wada Y, Takami Y, Tateishi M, Ryu T, Mikagi K and Saitsu H: The efficacy of continued sorafenib treatment after radiologic confirmation of progressive disease in patients with advanced hepatocellular carcinoma. PLoS One 11: e0146456, 2016.

25. BhayaniNH,Jiang Y,Hamed O,KimchiET,Staveley-O'Carroll KF and Gusani NJ: Advances in the pharmacologic treatment of hepatocellular carcinoma. Curr Clin Pharmacol 10: 299-304, 2015.

26. Stecker K, Vieth M, Koschel A, Wiedenmann B, Röcken C and Anders M: Impact of the coxsackievirus and adenovirus receptor on the adenoma-carcinoma sequence of colon cancer. $\mathrm{Br} \mathrm{J}$ Cancer 104: 1426-1433, 2011.

27. Jebar AH, Errington-Mais F, Vile RG, Selby PJ, Melcher AA and Griffin S: Progress in clinical oncolytic virus-based therapy for hepatocellular carcinoma. J Gen Virol 96: 1533-1550, 2015.

28. Wang YG, Huang PP, Zhang R, Ma BY, Zhou XM and Sun YF: Targeting adeno-associated virus and adenoviral gene therapy for hepatocellular carcinoma. World J Gastroenterol 22: 326-337, 2016. 
29. Bartlett DL, Liu Z, Sathaiah M, Ravindranathan R, Guo Z, He Y and Guo ZS: Oncolytic viruses as therapeutic cancer vaccines. Mol Cancer 12: 103, 2013.

30. Larson C, Oronsky B, Scicinski J, Fanger GR, Stirn M, Oronsky A and Reid TR: Going viral: A review of replication-selective oncolytic adenoviruses. Oncotarget 6: 19976-19989, 2015.

31. Pesonen S, Kangasniemi L and Hemminki A: Oncolytic adenoviruses for the treatment of human cancer: Focus on translational and clinical data. Mol Pharm 8: 12-28, 2011.

32. Choi JW, Lee JS, Kim SW and Yun CO: Evolution of oncolytic adenovirus for cancer treatment. Adv Drug Deliv Rev 64 720-729, 2012.

33. Wold WS and Toth K: Adenovirus vectors for gene therapy, vaccination and cancer gene therapy. Curr Gene Ther 13: 421-433, 2013.
34. Ma Y, Shurin GV, Peiyuan Z and Shurin MR: Dendritic cells in the cancer microenvironment. J Cancer 4: 36-44, 2013.

35. Gomez-Gutierrez JG, Nitz J, Sharma R, Wechman SL, Riedinger E, Martinez-Jaramillo E, Sam Zhou H and McMasters KM: Combined therapy of oncolytic adenovirus and temozolomide enhances lung cancer virotherapy in vitro and in vivo. Virology 487: 249-259, 2016.

36. Saito Y, Sunamura M, Motoi F, Abe H, Egawa S, Duda DG, Hoshida T, Fukuyama S, Hamada H and Matsuno S: Oncolytic replication-competent adenovirus suppresses tumor angiogenesis through preserved E1A region. Cancer Gene Ther 13: 242-252, 2006.

37. Cai Y, Liu X, Huang W, Zhang K and Liu XY: Synergistic antitumor effect of TRAIL and IL-24 with complete eradication of hepatoma in the CTGVT-DG strategy. Acta Biochim Biophys Sin (Shanghai) 44: 535-543, 2012. 